\title{
Demanding and Thinking for College to Build the Class with Research Learning
}

\author{
HU Fangchao ${ }^{1,2, a^{*}}$, WANG Zhenhui ${ }^{2, b}$ and QIU Yujun ${ }^{2, c}$ \\ ${ }^{1}$ Key Laboratory for Aerosol-Cloud-Precipitation of China Meteorological Administration, Nanjing \\ University of Information Science \& Technology, Nanjing 210044, China \\ ${ }^{2}$ School of Atmospheric Physics, Nanjing University of Information Science \& Technology, Nanjing \\ 210044, China \\ ahufc@nuist.edu.cn, beiap@nuist.edu.cn, 'cqyj@nuist.edu.cn
}

Keywords: Research study classes, Self-study ability, Innovation ability

\begin{abstract}
In order to achieve the goal that our own university and school are to develop into the teaching research one and the research teaching one, we combine the actual conditions of our major in the department to build up a class for research study in which college students are cultivated to graduates with the basic quality for research, who are charactered with the self-study and innovative abilities and rigorous, realistic approach, exploration and innovation towards scientific spirit, and who are able to discover, present, analyze and solve problems. In this paper we have an analysis of the requirements in college research study classes, and go on with the thinking of the development in future.
\end{abstract}

\section{Introduction}

It is of much importance to offer college students some basic scientific research guidance and systemic academic training. In many western countries the training has begun since kindergarten. For example, pupils in primary school had learned to write investigation report or paper by use of urban community library. On the contrary, Students in Chinese are lack of such training before college due to the great pressure for learning and entering entrance exams for higher schools. Even in college only in the last year, they just begin to practice literature searching i.e. how to search professional electronic literature using databases on Internet. It is in the last half year that their thesis actually carry with a bit of flavour of scientific training. However, being short of systemic academic training there is a big cognitive gap between a candidate and thesis advisor: the former feels completely in the dark on how to go on with his thesis subject which is hard to him, and the latter thinks that he has no idea of the subject which is difficult to deal with. So it is necessary that the related academic training should be started from freshmen ahead of schedule, and its intensity should be getting higher step by step. Then it is possible to make up for the training which is lost in primary and secondary school.

There have been many universities who carried on experiments in research-based teaching reform respectively, but they are mainly from schools, students and teachers, or from the teaching aspect of the relationship between teachers and students. Moreover, a class as a whole research object is considered at the class level, which is rare. So we provide some new attempts and consideration about how to construct a class of research-based learning for college undergraduates from the perspective of class in this paper.

The class is focused on the research learning-based and its the mid-and long-term goals. Our mid-term goal is to cultivate our undergraduates to be self-learning research, practical and compound talents with the potential to creatively develop, who have the abilities to discover, propose, analyze and solve problems independently. And our long-term goal is to make our graduates emerge a batch of distinguished alumni in domestic and foreign meteorological community like Grade 1977 and 197810 to 20 years later.

The key points in different phases: during phase I from freshmen to sophomore, the preliminary scientific research training should focus on the applied foundation of English and computer and the 
theoretic foundation of mathematics and physics. In this phase it is essential to get to know what the thinking methods used for scientific research is, what critical thinking is, and what is needed for creative research. In junior year for targeted specific subjects it is important to practice many skills: literature browsing, computer programming, professional paper reading, data calculating, data processing, charts and graphs visualizing etc. In the last phase, it is suggested that tutors may try to provide senior students research chances to write proposal, apply for some related projects or take part in his existing projects. Of course it is better to combine his research direction and interest with the thesis.

We think most undergraduates should take learning as the principal thing, and the academic foundation is not solid enough to directly participate in scientific projects, but it could not separate them from projects, and the related research training should be carried on. And it will set up this solid foundation: knowledge base, innovation consciousness, and skill training. In this process scientific norms are basic to scientific research training as they are helpful to scientific spirit and scientific morality. We pay much attention to creating environment of scientific research training, which is available to all students. And we would like to emphasize that the primary purpose of this training at the undergraduate level is not to publish papers but to take part below the edification of scientific research.

\section{Requirements and Thinking of Research Study Classes for Teachers and Students}

A teacher plays a critical role in the process of cultivating creative talents for he is the leader of teaching in the innovation education. As we know it is the one with innovative spirit and creative competence who is able to foster the students with innovation spirit and ability.

Teachers Need to Go on with Scientific Research Combining Practical Work with Social Needs. Because the scientific research itself is a kind of creative activity, only the innovative talent with creative spirit can achieve the success in scientific research. Instead, only by intensive scientific research can one get the exercise and training of innovative spirit and become full of creativity. So the scientific research leads the direction of our education, and guide the one of teachers' teaching. Then this requires them to shoulder the double burden of teaching and scientific research at the same time. Here is the basic concept between them, which are to benefit each other. If one teacher does not do research, he will not understand the actual situations of modern science and technology, update his own intellectual content, or adjust the knowledge structure. Thus students can not master the latest scientific knowledge, either. It is against his own development, and does not contribute to the students' innovative ability.

Teachers Need to Train Students Self-Learning Ability. The learning is a key between teaching and learning, and it is very important for students to learn how to teach themselves, too. Knowledge could be forgot, but the competence would accompany them a lifetime. With the rapid development of modern science and technology, knowledge updates very quick. University students can not master all the knowledge which could be used to handle all kinds of problems to meet in all circumstances in daily life and work in future, but if they have gained the ability to study, all the problem will become easy. A.N.Whitehead thinks that the central problem of all education is keeping knowledge alive, and preventing it from becoming inert, and that it is very valuable for students to go on with self development, which mostly takes place between the ages of 16 and 30 [1]. So we mean that one of the primary aims of college education is their being motivated and guided to go the way of self development and self realization. In other words, teachers teach them how to get what he needs by his own act. For teachers and students it must be solved how to transit from one way not to do more than being taught to another way without waiting for teachers to tell them how to do.

Teachers Should Pay Attention to Reform of the Ways and Means of Teaching. A classroom should be a platform, where communication and discussion of a certain question could be taken place between teachers and students, and which provides the opportunity to learn from each other. During this class, teachers often state the core and essence section of the course, succinctly sum the most important relevant knowledge dots for students to notice, and ignore all the intelligent stuff, which 
may need to teach themselves by virtue of questions, references or summaries after class. More common now, but not inadvisable, is reading from the prepared lecture or PPT. Teachers do not only spread knowledge, but also show the process of how knowledge originates and develops, which can inspire students. That is to say, some hot issues or inconclusive problems in academic frontier are introduced into the class, which is of great significance to do so, because it can stimulate their desire to enter into scientific research, broaden their horizons, and benefit from the methods of critical inquiry which could be applied to other scientific questions.

Teachers Should Have the Initiative to Guide Students. What college teachers teach students is not only expert knowledge, but is primarily a method of obtaining and processing that knowledge. This is not what teachers must do, but what students understand as course syllabus is defined. Teachers' work is mainly to guide. Not only so they provide students' knowledge and information, but the thinking and suggestion on the literacy, ability and development according to the personal situation. We have recognized the leading role in teaching, and then the same recognition of the central role to students in learning, just like what Carl R. Rogers said: young students themselves have interest and passion in learning, and teachers' task is to release and encourage them [2].

Teachers' Assessment of Students' learning Should Be Followed these Principles: Individuality Cultivation, Dynamic Contents and Process. At president the domestic assessment is still according to the score. College teachers also accommodate themselves to students, just like circling the scope of examination, highlighting the knowledge of the subject. If teachers permit students to cram for exams, and if any questions they set do not exceed the textbook, it would be not helpful for cultivating students' innovative consciousness, nor the creative ability. By exams teachers guide students to learn what they have to learn, what they should learn. Even though some may pass the exam or get a high score by rote, they cannot learn the things they really need, for it is no benefit to the development of students in the long run.

Most Modern College Students Have Many Drawbacks of not Knowing How to Learn. In learning style, they rely on teachers too much, and they are independent too little; in thinking way, seeking common ground too much, seeking difference too little; in learning state, blind obedience too much, doubt too little; in learning level, inheritance too much, innovation too little; in learning emotion, exam oriented too much, interest too little. Students should be trained to focus on the outline, to emphasize the overall situation of learning, and not to stick to the details so as to improve the efficiency of learning [3]. Some details may not be found out early, but when they understand from the overall situation later, the details of questions could be naturally resolved. Furthermore, if they understand local something from the general, the understanding will be deeper. Students should have learned to take effective notes, which have to be on the basis of understanding at first. Next they can write a summary for their learning according to what they listened in class and what they thought after class. After some time for the summary they can separate the chaff from the wheat, and compile the learning outcomes in this stage. Thus it is the way it could be an intact note. They have to learn to recall the lecture in time, so new knowledge can be internalized into their own knowledge quickly after a serious thought and assimilation. Besides, it is suggested that a special note is prepared as a problem one. As some difficult questions cannot be solved immediately, students have to write the problems down. They have to do this when reading articles or papers, especially for those situations: something they do not understand, something is in doubt, something has inspired them, or something needs to discuss with others. As we know, often in the discussion, a variety of thinking sparks could be burst out from the collision of different viewpoints, and it is very beneficial for them to enhance their thinking ability.

College Students Should Think Independently and Pursue the Truth with Suspicion. Learning starts from thinking, while thinking starts from doubts. In order to develop their independent thinking and exploration, curiosity of questions, and a strong desire for new knowledge, they must have the attitude of active thinking and critical spirit. Firstly they will have questionable consciousness. Questions refer to the objective existence of contradictions, and they are the life of the subject and the essence of theory, so college students should have questions in their heart often. Students must be apt to find questions and dare to ask more difficult ones. Only if they have questions, 
it will be possible to get them started, and the creation is always being produced during the process of solving them [4]. The vitality of creative thinking lies in doubt. As without doubt there would be no discovery, so without critique, there would be no creation. According to the viewpoint of modern educational ideology, the undergraduate teaching-learning process is learning and discovery. Learning to find something out is a main aim, as the factors in discovery are penetrated into the every aspect of the teaching procedures, and they are running through the entire teaching process. Secondly, students must be good at thinking about problems [5]. There always are distinctions between true and false, deep and shallow, virtual and real problems. The knowledge will change along with the time. Any knowledge must be from a concrete problem, but one of the most critical parts of intellectual content is to learn to think about the question, to study its logic, to understand the law inside, and to have a good grasp of it, not by rote. Lastly, from the perspective of problem oriented, the college teaching must end up cultivating two key abilities: one is to discover and put problems, the other is to analyze and solve them.

\section{Summary}

Education is a long process, so we should take a long-term view to think about college education, and we must not treat and engage in the innovation of science \& technology with a strong mind of seeking quick success and making a quick buck. Chinese traditional education is a kind of education with acceptance and inheritance; it lays emphasis on imparting the existing cultural and scientific knowledge. Current educational situation is basically in the process of transition from traditional teacher-centered knowledge-feeding teaching mode, which is lack of personality liberation and independent spirit, to a new learner-centered diversified teaching mode, which aims at students' all-round and long-term development.

Building a class with research learning oriented will be helpful to accelerate this process, to make college students participate in scientific research and innovative activities earlier, to guide them to release their innovation potential, to improve the environment for group learning, to enhance their overall level of the class, and to increase the competition capability of them to enter the society.

\section{Acknowledgements}

This research is supported by Teaching Reform Project NUIST China (No:2013JY010, 2015JY027)

\section{References}

[1] A.N.Whitehead. The aims of education and other essays. New York: Macmillan, 1929

[2] C.R.Rogers. Personal thoughts on teaching and learning. Merrill-palmer Quarterly 1957, 3(4): 241-243

[3] M.J. Adler \& C.V. Doren How to read a book.Yohan, 1972

[4] M.N. Browne \& S.M.Keeley Asking the right questions: a guide to critical thinking. $7^{\text {th }}$ Edition, 2004.

[5] B.N.Moore,\& R.Parker Critical thinking $10^{\text {th }}$ Edition, 2012 